\title{
Dermoscopy of granuloma faciale: a description of a new finding*
}

\author{
Márcio Martins Lobo Jardim${ }^{1}$, Juliana Uchiyama ${ }^{1}$, Priscila Kakizaki ${ }^{1}$, Neusa Yuriko Sakai Valente ${ }^{1}$
}

DOI: http:/ / dx.doi.org/10.1590/abd1806-4841.20187017

\begin{abstract}
Granuloma faciale is a rare, chronic dermatologic disorder, which mainly affects the face. Recently, dermoscopy has been demonstrated as an important ancillary tool on the clinical diagnosis of facial dermatoses. We report two cases of granuloma faciale with yellow areas on dermoscopy that was not yet described in the literature, corresponding to abundant hemosiderin on histopathological examination.
\end{abstract}

Keywords: Dermoscopy; Facial dermatoses; Hemosiderin

\section{INTRODUCTION}

Granuloma faciale (GF) is a rare dermatologic condition, characterized clinically by violaceous plaques on the face. It has a chronic course and typically affects middle-aged men. ${ }^{1}$ Dermoscopy is a well-established non-invasive method for the diagnosis of melanocytic lesions, increasingly used for other skin conditions in clinical practice. ${ }^{2}$ We report two cases of GF that presented with yellowish areas on dermoscopy, not yet described in the literature.

\section{CASE 1}

A 33-year-old male patient, previously healthy, reported the appearance of an asymptomatic erythematous-violaceous lesion on the face 3 years back. On physical examination, there was an erythematous-violaceous plaque with nodules close to the right nasolabial fold (Figure 1A). On dermoscopy there were linear, branching vessels associated to marked follicles, white streaks in many directions and a yellowish area that became more obvious after the application of immersion fluid and contact of the dermoscope with the skin (Figure 1B). A biopsy was taken of the yellowish area mentioned, and the histopathology revealed an increased deposition of hemosiderin in the papillary dermis demonstrated by Prussian blue staining, as well as a mixed, dense infiltrate formed by lymphocytes, histiocytes, plasma cells, eosinophils and neutrophils with leukocytoc lasia in the papillary and reticular dermis and the presence of a grenz zone (Figures 2 and 3). Due to the thickness of the lesion, monthly injections of triamcinolone were administered as treatment $(2.5 \mathrm{mg} / \mathrm{ml})$.

\section{CASE 2}

A 68-year-old female patient reported the appearance of an asymptomatic erythematous-violaceous lesion on the face 10 months back. She had a past history of hypothyroidism treated daily with oral levothyroxine $(75 \mu \mathrm{g})$. physical examination revealed a well-defined erythematous-violaceous plaque on the left malar region (Figure 4A). On dermoscopy, thick and branching vessels in the periphery and marked follicles were seen, associated to a yellow-brown background in the center of the lesion (Figure 4B). Biopsy confirmed the diagnosis of GF. During clinical follow-up, the lesion regressed spontaneously and therefore we opted not to treat.

\footnotetext{
Received 13 February 2017.

Accepted 28 August 2017.

* Study conducted at the Service of Dermatology, Hospital do Servidor Público Estadual de São Paulo, São Paulo (SP), Brazil.

Financial support: None.

Conflict of interests: None.

1 Service of Dermatology, Hospital do Servidor Público Estadual de São Paulo, São Paulo (SP), Brazil.
}

MAILING AdDRESS:

Márcio Martins Lobo Jardim

E-mail: martinslobojardim@gmail.com

C2018 by Anais Brasileiros de Dermatologia 

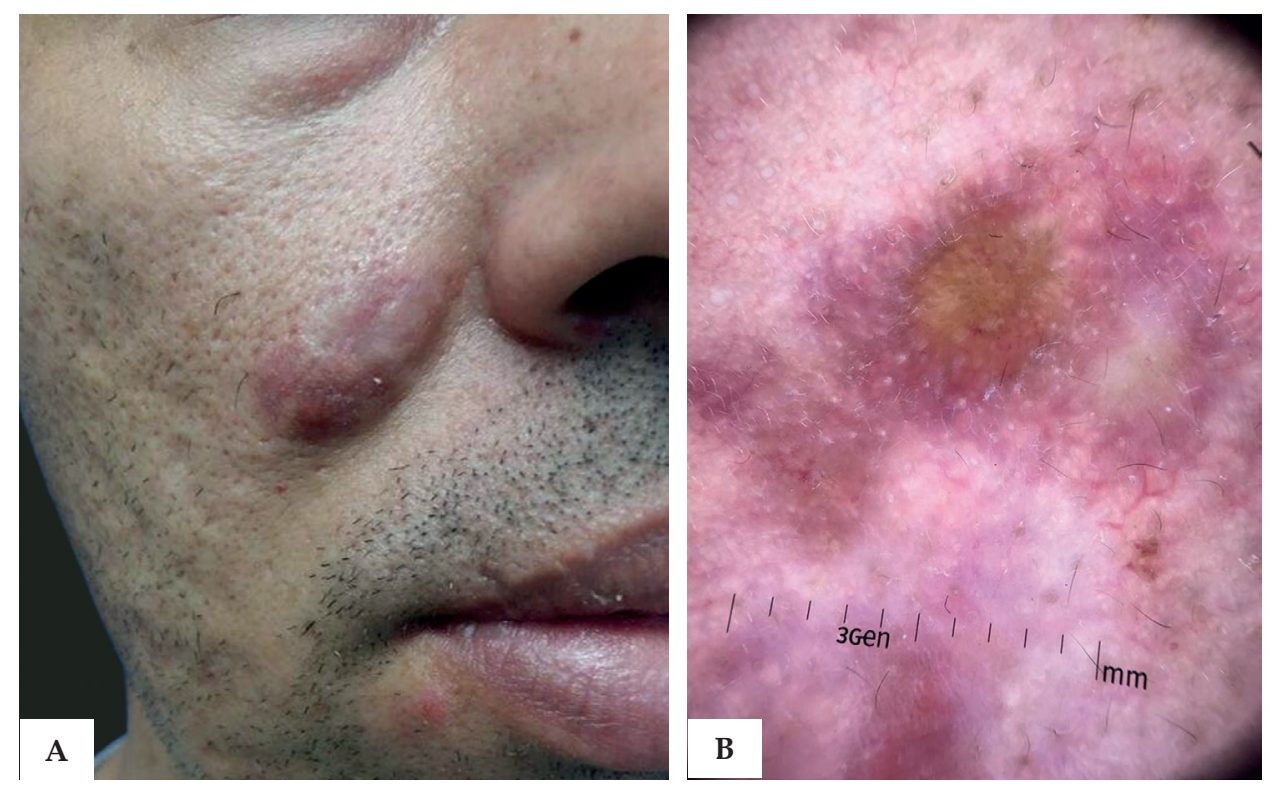

Figure 1: A - Erythematous-violaceous plaque near the right nasolabial fold.

B - Yellowish area in the center of the lesion associated to marked follicles, irregular white streaks and background erythema (contact dermoscopy with immersion fluid, $\mathrm{x} 10)$

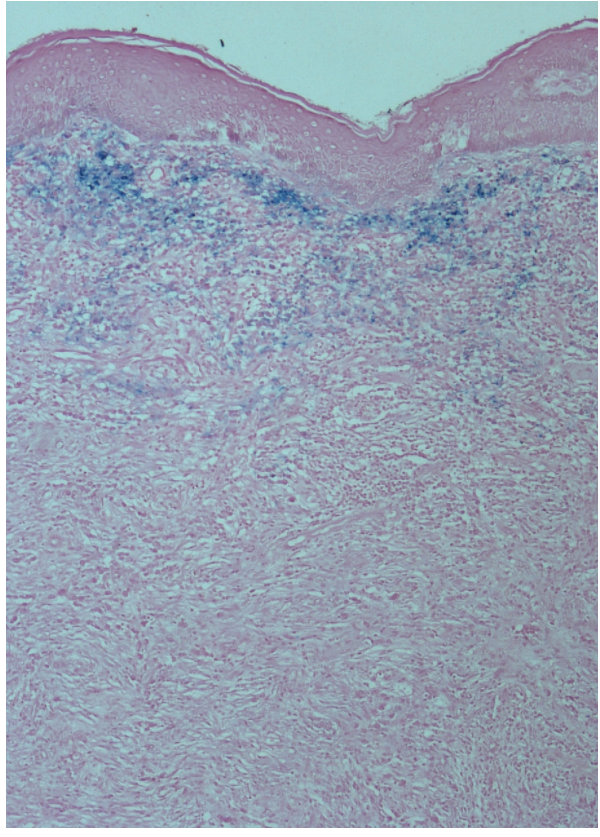

FiguRe 2:

Abundant hemosiderin stained by Prussian blue (Perls, x100)

\section{DISCUSSION}

GF is an uncommon condition in clinical practice. Its first description was made by Wigley in 1945. It is a condition of unknown etiology and good prognosis. Its importance relies on the aesthetic aspects. Besides, it is essential to rule out other facial skin conditions in the diagnostic approach of GF such as sarcoid, lupus erythematosus, lymphoma and Jessner's lymphocytic infiltrate. ${ }^{1}$

Caldarola et al., in 2012, described for the first time the dermoscopy of GF when they reported the case of a 72-year-old patient with marked follicles, gray background associated to orthogonal white streaks and irregular branching vessels. Lallas et al. published, in 2012, a case in which the findings were, besides marked follicles and branching linear vessels, brown globules. In 2013, Teixeira et al.

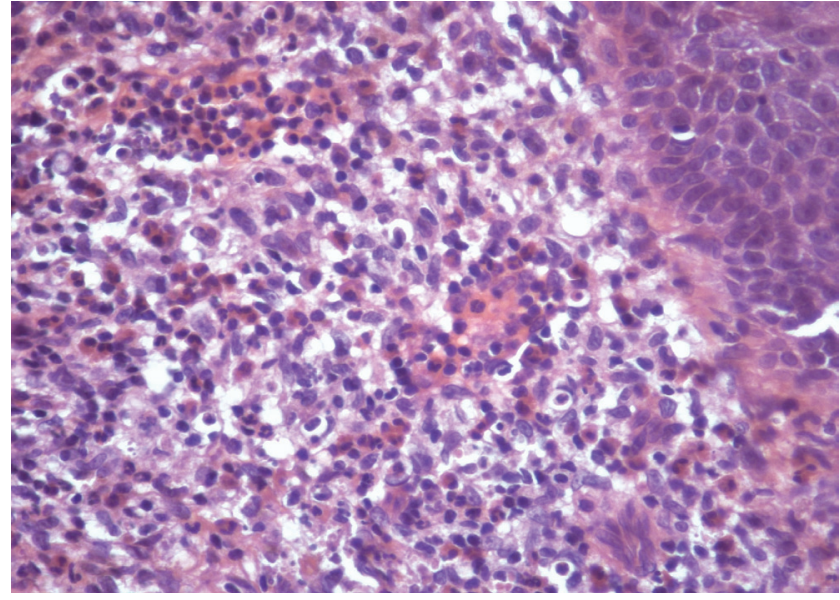

FiguRE 3: Mixed infiltrate formed by lymphocytes, histiocytes, plasma cells and neutrophils and a grenz zone (Hematoxylin \& eosin, $\mathrm{x} 400)$

reported the case of a 40 -year-old patient with a similar dermoscopic description to the previous cases. ${ }^{3-5}$

The larger study on the theme is by Lallas et al. (2014) and analyzed the dermoscopy of five GF patients. The common description to all cases studied was marked follicles, linear branching vessels and perifollicular white halo. ${ }^{6}$

The dermoscopic findings of the cases here described are in accordance to those observed in the previous publications; however, we highlight an additional feature that was not reported before. In both patients of this study, an amorphous yellowish or yellow-brown area was found, which correlated to the presence of abundant hemosiderin on histology, highlighted by Prussian blue staining in the his- 

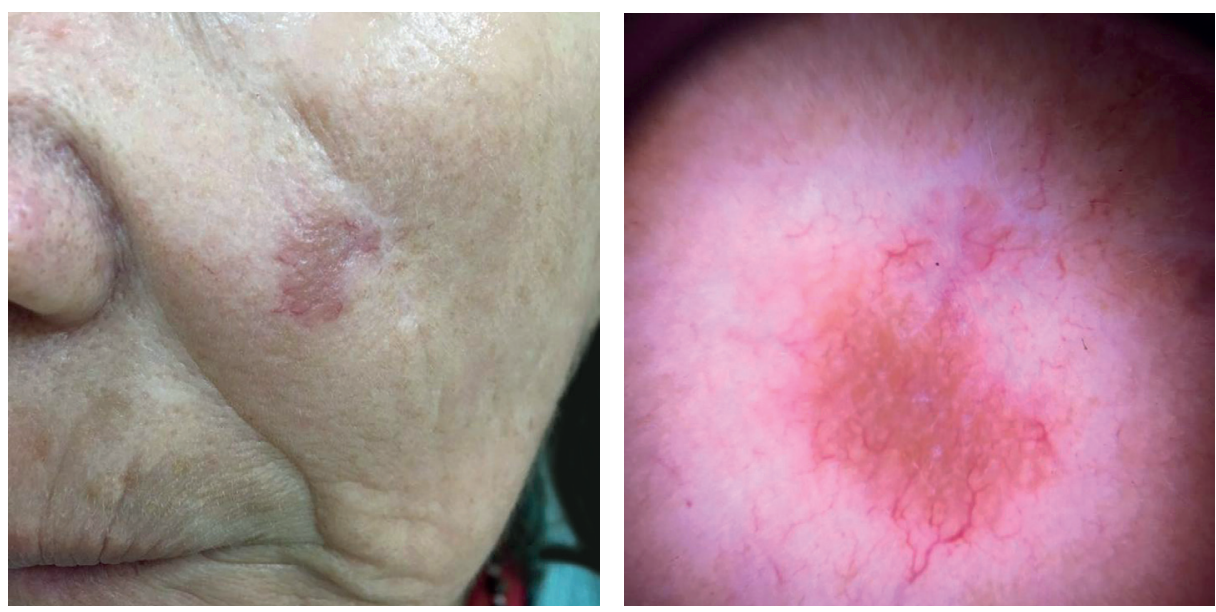

Figure 4: A. Erythematous-violaceous plaque on the left malar region. B. Linear branching vessels, marked follicles, irregular white streaks and yellow-brown area in the background (noncontact dermoscopy, x10)

tological sections. In 2012, Lallas et al. had already described one case of GF with brown globules, which were interpreted as likely to be associated to hemosiderin by the authors, even though a histological correlation proving this theory had not been established.

Hemosiderin is a common finding on histology of GF. In a series of 66 cases published by Ortonne et al. in 2005, the presence of hemosiderin was seen in $70 \%$ of the specimens analyzed. On dermoscopy, the presence of hemosiderin has already been described in cases of lichen aureus as yellow-brown areas similar to the finding here described. ${ }^{1,7}$

Thus, both cases here reported serve as a premise to suggest that amorphous yellow or yellow-brown areas can appear in GF due to the high frequency of hemosiderin deposited in these lesions. Therefore, this finding should be taken into consideration for the dermoscopic diagnosis of GF, along with the other features already previously described in the literature. $\square$

\section{REFERENCES}

1. Ortonne N, Wechsler J, Bagot M, Grosshans E, Cribier B. Granuloma faciale: a clinicopathologic study of 66 patients. J Am Acad Dermatol. 2005;53:1002-9.

2. Errichetti E, Stinco G. Dermoscopy in General Dermatology: A Practical Overview. Dermatol Ther (Heidelb). 2016;6:471-507.

3. Caldarola G, Zalaudek I, Argenziano G, Bisceglia M, Pellicano R. Granuloma faciale: a case report on long-term treatment with topical tacrolimus and dermoscopic aspects. Dermatol Ther. 2011;24:508-11.

4. Teixeira DA, Estrozi B, lanhez M. Granuloma faciale: a rare disease from a dermoscopy perspective. An Bras Dermatol. 2013;88:97-100.

AUTHORS CONTRIBUTION
$\begin{array}{lll}\text { Márcio Martins Lobo Jardim } & \text { (D) ORCID } & 0000-0002-8431-3607 \\ \text { Elaboration and writing of the manuscript } & & \\ \text { Juliana Uchiyama } & \text { iD ORCID } & 0000-0001-8340-7903 \\ \text { Elaboration and writing of the manuscript } & & \end{array}$

5. Lallas A, Sidiropoulos T, Lefaki I, Tzellos T, Sotiriou E, Apalla Z. Photoletter to the editor: dermoscopy of granuloma faciale. J Dermatol Case Rep. 2012;6:59-60.

6. Lallas A, Argenziano G, Apalla Z, Gourhant JY, Zaballos P, Di Lernia V, et al. Dermoscopic patterns of common facial inflammatory skin diseases. J Eur Acad Dermatol Venereol. 2014;28:609-14.

7. Portela PS, Melo DF, Ormiga P, Oliveira FJC, Freitas NC, Bastos Jr CS. Dermoscopy of lichen aureus. An Bras Dermatol. 2013;88:253-5.

How to cite this article: Jardim MML, Uchiyama J, Kakizaki P, Valente NYS. Dermoscopy of granuloma faciale: a description of a new finding. An Bras Dermatol. 2018;93(4):587-9. 